Proc. Indian Acad. Sci. (Earth Planet. Sci.), Vol. 94, No. 1, March 1985, pp. 1-5.

(C) Printed in India.

\title{
Tracing quartz through the environment
}

\author{
D LAL* and J R ARNOLD** \\ *Scripps Institute of Oceanography, La Jolla, CA 92093, USA \\ Also Physical Research Laboratory, Ahmedabad 380009, India \\ **Calif. Space Institute, A-021, University of California, San Diego, La Jolla, CA 92093, USA \\ MS received 24 December 1984
}

\begin{abstract}
Quartz, $\mathrm{SiO}_{2}$, a pure mineral with tight crystal structure, is widespread in rocks and soil. Cosmic rays produce ${ }^{10} \mathrm{Be}\left(t_{1 / 2}=1.5 \times 10^{6}, \mathrm{yr}\right)$ and ${ }^{26} \mathrm{Al}\left(t_{1 / 2}=7.05 \times 10^{5} \mathrm{yr}\right)$ in quartz exposed at or near the earth's surface. The use of accelerator mass spectrometry permits measurement of these nuclides in samples exposed at sea level for typical periods. In situ production makes interpretation relatively straightforward. Potential applications include age determination, measurement of erosion and deposition rates, and use as a tracer for continental weathering processes.
\end{abstract}

Keywords. Quartz; cosmic ray produced isotopes; erosion; accelerator mass spectroscopy.

The development of accelerator mass spectrometry (AMS) has allowed measurement of ${ }^{10} \mathrm{Be}$ in natural materials (Brown 1984). The ${ }^{10} \mathrm{Be}$ atoms investigated so far are those mainly produced in the atmosphere and admixed into these materials. Monaghan et al (1983) and Pavich et al (1984) have shown the value of this technique for soil deposition studies, but the processes involved are complex. In situ production (Jha and Lal 1981; Yiou et al 1984), offers an attractive alternative for such studies. We discuss here the in situ production in quartz, which seems to offer several advantages.

Quartz, the common form of $\mathrm{SiO}_{2}$, is an ideal target material for production of two longlived isotopes, ${ }^{10} \mathrm{Be}$ and ${ }^{26} \mathrm{Al}$. Impurities, including $\mathrm{Al}$, are usually present at or below a few hundred ppm. The intact crystal is impermeable to water and ions. It is abundant and easy to isolate. The two isotopes, ${ }^{10} \mathrm{Be}$ and ${ }^{26} \mathrm{Al}$, are produced at rates of the order of 10 atoms/gram year at sea level, permitting a measurement in about 10 grams of quartz exposed for $10^{4}$ years.

The production rates of ${ }^{10} \mathrm{Be}$ and ${ }^{26} \mathrm{Al}$ in diverse target materials can be estimated fairly accurately (Jha and Lal 1981; Lal and Peters 1967). For a more comprehensive recent treatment, see Lal et al (1985).

The nucleonic isotope production dominates in any material exposed at altitudes above sea level. The energy spectrum of nucleons at any given latitude remains invariant in the atmosphere at depths exceeding $200 \mathrm{~g} \mathrm{~cm}^{-2}$, the so-called nuclear cascade equilibrium region. The depth variation of production within a rock exposed in the equilibrium region will closely follow the absorption mean free path, observed in the atmosphere. Its value varies from 150 to $170 \mathrm{~g} \mathrm{~cm}^{-2}$, decreasing with increasing latitude, reaching a constant value for $50^{\circ}-90^{\circ}$ latitudes. The estimated production rates of ${ }^{10} \mathrm{Be}$ and ${ }^{26} \mathrm{Al}$ in quartz are given in table 1 for the equilibrium region at high latitudes. For lower geomagnetic latitudes, production rates in table 1 can be scaled using the latitude-altitude variation given by Lal and Peters (1967) in figure 4 for ${ }^{10} \mathrm{Be}$ and other isotopes. 
Table 1. In situ cosmic ray production rates of ${ }^{10} \mathrm{Be}$ and ${ }^{26} \mathrm{Al}$ in quartz, at geomagnetic latitudes $50^{\circ}-90^{\circ}$

\begin{tabular}{|c|c|c|c|c|c|}
\hline \multirow{3}{*}{$\begin{array}{c}\text { Altitude } \\
(\mathbf{k m})\end{array}$} & \multirow{3}{*}{$\begin{array}{c}\text { Atmospheric } \\
\text { pressure, } p \\
\left(\mathrm{~g} \mathrm{~cm}^{-2}\right)\end{array}$} & \multicolumn{3}{|c|}{ Atoms $/ \mathrm{g} \mathrm{SiO}{ }_{2} \cdot y r$} & \multirow{3}{*}{$\begin{array}{c}{ }^{10} \mathrm{Be} /{ }^{26} \mathrm{Al} \\
\text { ratio at } \\
\text { production }\end{array}$} \\
\hline & & \multicolumn{2}{|c|}{$\begin{array}{l}\text { Nucleon } \\
\text { spallation }\end{array}$} & \multirow{2}{*}{$\begin{array}{c}\text { Negative } \\
\text { mu-meson } \\
\text { capture* } \\
{ }^{26} \mathrm{Al}\end{array}$} & \\
\hline & & ${ }^{10} \mathrm{Be}$ & ${ }^{26} \mathrm{Al}$ & & \\
\hline $\begin{array}{c}0 \\
\text { (Sea level) }\end{array}$ & 1030 & 6.5 & 21 & $6-5$ & 0.236 \\
\hline 1 & 925 & 15 & 48 & $10-0$ & 0.258 \\
\hline 3 & 730 & 63 & 210 & $22 \cdot 0$ & 0.271 \\
\hline 5 & 550 & $2 \times 10^{2}$ & 670 & $46 \cdot 0$ & 0.279 \\
\hline
\end{tabular}

\footnotetext{
- Negative mu-meson capture in $\mathrm{SiO}_{2}$ does not lead to production of ${ }^{10} \mathrm{Be}$. At depths exceeding $1000 \mathrm{~g} \mathrm{~cm}^{-2}$ below sea level ${ }^{10} \mathrm{Be}$ production due to nuclear interactions of fast mu-mesons becomes dominant (Jha and Lal 1981; Lal and Peters 1967). The production rate of ${ }^{26} \mathrm{Al}$ due to negative mu-meson capture is based on procedures discussed earlier (Jha and Lal 1981; Winsberg 1956; Hampel et al 1975), that for nuclear spallation is based on published cross sections (Tobailem 1981) for formation of ${ }^{26} \mathrm{Al}$ from proton bombardment of ${ }^{28} \mathrm{Si}$ and the nucleon energy spectrum in the atmosphere (Lal and Peters 1967).
}

The slow mu-meson component attenuates with a larger absorption mean free path, $\Lambda=245 \mathrm{~g} \mathrm{~cm}^{-2}$. Capture of negative mu-mesons produces ${ }^{26} \mathrm{Al}\left(\mu^{-}+{ }^{28} \mathrm{Si} \rightarrow 2 \mathrm{n}\right.$ $\left.+{ }^{26} \mathrm{Al}\right) .{ }^{10} \mathrm{Be}$ is not produced by negative mu-meson capture in oxygen, but fast mu-meson coulombic interactions can produce ${ }^{10} \mathrm{Be}$ from oxygen. At depths exceeding $1000 \mathrm{~g} \mathrm{~cm}^{-2}$ below sea-level, production of ${ }^{10} \mathrm{Be}$ and ${ }^{26} \mathrm{Al}$ from fast meson interactions in $\mathrm{SiO}_{2}$ becomes dominant (Jha and Lal 1981). Nucleonic production becomes unimportant at these depths. We have considered only cosmogenic production since radiogenic alphas and neutrons do not contribute to production of ${ }^{10} \mathrm{Be}$ or ${ }^{26} \mathrm{Al}$ in quartz.

For atmospheric depths, $(200-1030) \mathrm{g} \mathrm{cm}^{-2}$, isotope production rates due to capture of negative mesons can be estimated from values in table 1 using an absorption mean free path of $245 \mathrm{~g} \mathrm{~cm}^{-2}$. At depths below sea level, the same exponent continues up to $600 \mathrm{~g} \mathrm{~cm}^{-2}$, the absorption mean free path becomes larger at greater depths, but fast mu-meson interactions dominate.

Calculations in table 1 are based on the procedures developed earlier (Lal and Peters 1967). The energy spectrum of nucleons in the troposphere is known fairly well. Primary uncertainty arises in particular due to non-availability of the neutron excitation function for formation of ${ }^{10} \mathrm{Be}$ from oxygen; most of the ${ }^{10} \mathrm{Be}$ production in the troposphere is expected to occur due to neutron interactions. However, based on observations of fall-out of ${ }^{10} \mathrm{Be}$ from the atmosphere, and also of ${ }^{10} \mathrm{Be}$ concentrations in meteorites, one can make fairly good predictions for the ${ }^{10} \mathrm{Be}$ production rates. This procedure has been recently adopted by Lal et al (1985); they obtained for the average yields of ${ }^{10} \mathrm{Be}$, values of $2.5,2.2$ and $1.5 \%$ respectively in nuclear disintegrations in $\mathrm{C}, \mathrm{N}$ 
and $\mathrm{O}$ due to fast nucleons, in the troposphere. The average yield of ${ }^{10} \mathrm{Be}$ in disintegrations in $\mathrm{Si}$ is calculated to be $0.5 \%$.

Our calculations differ widely from those published earlier by Yokoyama et al (1977), for both ${ }^{10} \mathrm{Be}$ and ${ }^{26} \mathrm{Al}$. Comparing our values with those for granite $\left(\mathrm{SiO}_{2}=73 \%\right)$, we find that their production rates are lower and higher by factors of about 3 and 2 for ${ }^{10} \mathrm{Be}$ and ${ }^{26} \mathrm{Al}$ respectively. They estimate a value of 0.048 for the ${ }^{10} \mathrm{Be} /{ }^{26} \mathrm{Al}$ ratio at production (due to nucleons), which has to be compared with our value of 0.31 .

Comparing our production estimates with the values available in literature, we note that Yiou et al (1984) found the lowest ${ }^{10} \mathrm{Be} /{ }^{26} \mathrm{Al}$ ratio in Libyan desert glass, $0 \cdot 37$. Two other glasses studied, Australites and Darwin glass, had values of $>4.0$ and 1.37 respectively. Our estimated ratio at production corresponds to a minimum value of 0.24 for the ${ }^{10} \mathrm{Be} /{ }^{26} \mathrm{Al}$ ratio, which is not inconsistent with the value observed for Libyan glass. Our calculated ratio at production is also close to that expected from observed values in meteorites.

The calculated isotope ratio ${ }^{10} \mathrm{Be} /{ }^{26} \mathrm{Al}$ at production in $\mathrm{SiO}_{2}$ is given in table 1; the calculation is uncertain by $30 \%$ or more. Still the ratio is expected to remain constant at production within rather narrow limits, $\pm 10 \%$, for a variety of exposure conditions, as long as the sum of atmospheric depth and the depth within the rock does not exceed $1300 \mathrm{~g} \mathrm{~cm}^{-2}$. This postulate can of course be verified experimentally. Davis and Schaeffer (1955) measured ${ }^{36} \mathrm{Cl}$ in a rock sample bearing glacial scour marks, and hence not appreciably eroded since post-glacial exposure. Such samples are suitable for testing the variation with depth of ${ }^{26} \mathrm{Al}$ and ${ }^{10} \mathrm{Be}$ production.

Because the production ratio is or can be known, one important application is as a dating method. The applicable half-life, for an exposure in fixed geometry, is calculated from $\lambda=\lambda_{\mathrm{Al}}-\lambda_{\mathrm{Be}}$. This corresponds to a half-life of $1.3 \times 10^{6}$ years. The expected error is defined by the predictability of the ratio at the end of bombardment, and the measurement error. A precision of $3 \times 10^{5}$ years or better seems attainable.

One can consider a variety of models for in situ exposure of quartz grains, involving cosmic ray exposure prior to their being dislodged from the host rock, and subsequent irradiation during transport through the fluvial systems or by wind and burial. Trajectories will be complex, but two elements are important, and common to most models: (i) rock weathering and release of quartz grains; (ii) burial of quartz grains by sedimentation.

Rock weathering leads to an in situ production dependent on altitude and erosion rate. The expected concentration of an isotope $i$ in a rock at atmospheric pressure $p\left(\mathrm{~g} \mathrm{~cm}^{-2}\right)$, in a sample at depth $x(\mathrm{~cm})$ from surface, $N_{i}(p, x)$ is given by:

$$
N_{i}(p, x)=P_{i}(1030) \exp [(1030-p-\rho x) / \Lambda] \cdot \frac{1}{\lambda+\rho \varepsilon / \Lambda}
$$

where $P_{i}(1030)$ is the isotope production rate in the surface of a rock exposed at sea level and $\rho$ is the density of the rock. Equation (1) assumes a steady state erosion rate of $\varepsilon \mathrm{cm} \mathrm{yr}^{-1}$. The characteristic time of irradiation in an eroding rock is $\Lambda /(\Lambda \lambda+\rho \varepsilon)$. Model calculations for a range of erosion rates are given in table 2 .

The other case of irradiation is that of a grain buried by material sedimenting on it. Any initial amount $N_{i}(0)$, in the grain will then decay exponentially. The total amount including the in situ production in a grain buried to a depth $x$ by a constantly 
Table 2. Expected ${ }^{10} \mathrm{Be}$ and ${ }^{26} \mathrm{Al}$ concentrations in a rock exposed at sea level, eroding at a steady rate.

\begin{tabular}{cccc}
\hline $\begin{array}{c}\text { Erosion rate } \\
\left(\mathrm{cm} \mathrm{yr}^{-1}\right)\end{array}$ & $\begin{array}{c}{ }^{10} \mathrm{Be} \text { concentration } \\
\text { (atoms/g) }\end{array}$ & $\begin{array}{c}\text { Effective time } \\
\text { or irradiation } \\
\text { for }{ }^{10} \mathrm{Be}(\mathrm{yrs})\end{array}$ & $\begin{array}{c}\text { Ratio } \\
{ }^{10} \mathrm{Be} /{ }^{26} \mathrm{Al}\end{array}$ \\
\hline $10^{-5}$ & $9.7 \times 10^{6}$ & $1.5 \times 10^{6}$ & 0.46 \\
$10^{-4}$ & $2.3 \times 10^{6}$ & $3.6 \times 10^{5}$ & 0.31 \\
$10^{-3}$ & $2.7 \times 10^{5}$ & $4.2 \times 10^{4}$ & 0.26 \\
$10^{-2}$ & $2.8 \times 10^{4}$ & $4.3 \times 10^{3}$ & 0.26 \\
$10^{-1}$ & $2.8 \times 10^{3}$ & $4.3 \times 10^{2}$ & 0.26 \\
\hline
\end{tabular}

accumulating sediment $N_{i}(p, x)$, is given by:

$$
\begin{aligned}
N_{i}(p, x)= & N_{i}(0) \exp (-\lambda x / s)+\frac{P_{i}(1030) \exp [(1030-p) / \Lambda]}{\rho s / \Lambda-\lambda} . \\
& \times[\exp (-\lambda x / s)-\exp (-\rho x / \lambda)],
\end{aligned}
$$

where the rate of sedimentation is $\mathrm{s} \mathrm{cm} \cdot \mathrm{yr}^{-1}$.

We will now consider some direct applications of studies of ${ }^{10} \mathrm{Be}$ and ${ }^{26} \mathrm{Al}$ activities in quartz. A clear cut case is the deposition of aeolian quartz in deep sea or lake sediments. In this case there is essentially no production within the sediment and the age of the sediment is then given by $1.9 \times 10^{6} \ln \left(R_{0} / R_{m}\right)$, where $R_{0}$ is the ${ }^{10} \mathrm{Be} /{ }^{26} \mathrm{Al}$ ratio at production and $R_{m}$ that measured. From tables 1 and 2 , it can be seen that the initial ratio is expected to be close to 0.26 for grains released in the weathering process. Continental erosion rates range upward from about $10^{-4} \mathrm{~cm} \mathrm{yr}^{-1}$ to much higher values.

Except for the very slowest erosion and deposition rates $\left(10^{-4} \mathrm{~cm} / \mathrm{yr}^{-1}\right.$ or less), and for loose sand deposits which may have quite complex histories, a complete erosiondeposition cycle will be completed in a time short compared to the effective half-life. Thus the ratio after deposition should be predictable. Studies of ${ }^{10} \mathrm{Be} /{ }^{26} \mathrm{Al}$ ratios in quartz in sediments promise to yield ages of the sediments, i.e. the time since the episodes of exposure at or near the surface.

In the unusual case where either erosion or deposition is very slow and steady, the ratio will shift as the duration of bombardment becomes comparable to the half-life. Table 2 illustrates this. For desert or beach sands, many episodes of erosion, transport, and deposition may take place; the ratio will have some value between that for production in the original rock (altered by decay) and that for the present day. Because the original production was (usually) at a higher altitude, this episode may weigh more heavily.

Individual source regions for sediments can be expected to have distinctive ${ }^{10} \mathrm{Be}$ and ${ }^{26} \mathrm{Al}$ content, depending on altitude and exposure history. These may serve as markers, assisting in the understanding of ocean and lake sediments, and the climatic regimes in which they formed. Identification and dating both should be possible in favourable cases.

The depositional history of any soil sequence or sedimentary rock can be studied in great detail by measuring ${ }^{10} \mathrm{Be}$ and ${ }^{26} \mathrm{Al}$ in quartz grains as a function of depth. $\mathrm{A}$ 
monotonic change will indicate a continuous sequence. Interruptions can be easily seen. (Supplementary information can be obtained from the study of chemically adsorbed

${ }^{10} \mathrm{Be}$ on soil grains. Note that essentially no ${ }^{26} \mathrm{Al}$ is expected from this source.)

Exposure dating of strata or horizons on a million year time scale using quartz, may have a wide range of applications, since the half-life falls between ${ }^{14} \mathrm{C}$ and the longlived radioactive clocks. While the difficulties can only be understood by experimental study, the broad distribution of quartz and the expected constancy of the production ratio suggest that the method has great promise. Early man sites represent one intriguing possibility (Curtis 1981). If a present surface horizon to be dated can be traced to a present depth of 5-10 meters, quartz samples may be suitable for dating the most important period of original surface exposure.

On other planetary bodies, where alteration processes are less active, a wider range of minerals can be used. This has already been demonstrated in lunar samples (Nishiizumi et al 1979).

\section{Acknowledgements}

We thank Gustaf Arrhenius, Louis Brown, Albert Engel, Miriam Kastner, S. Krishnaswami, Roy Middleton, Douglas Macdougall, Kanihiko Nishiizumi and E. L. Winterer for valuable discussions on the problem.

\section{References}

Brown L 1984 Annu. Rev. Earth Planet. Sci. 1239

Brown L, Sacks I S, Tera F, Klein J and Middleton R 1981 Earth Planet. Sci. Lett. 55370

Curtis G H 1981 Phil. Trans. R. Soc. London B292 7

Davis R and Schaeffer O A 1955 Ann. N. Y. Acad. Sci. 62105

Hampel W, Takagi J, Sakamoto K and Tanaka S 1975 J. Geophys. Res. 803757

Jha R and Lal D 1981 Proc. Second Symp. on Natural Radiation Environment (eds) K G Vohra, K C Pillai, U C Mishra and S Sadasivan (New Delhi: Wiley Eastern Press) p. 629

Lal D 1984 in Abstracts Workshop on Cosmogenic Nuclides, Los Alamos National Laboratory, (Lunar and Planetary Science Institute, Houston TX)

Lal D, Nishiizumi K and Amold J R 1985 (in preparation)

Lal D and Peters B 1967 in Handbuch der Physik, X LVI/2 (Berlin: Springer Verlag) p. 551

Monaghan M C, Krishnaswami S and Thomas J H 1983 Earth Planet. Sci. Lett. 6551

Nishiizumi K, Imamura M, Kohl C P, Murrell M T, Arnold J R and Russ, G P III 1979 Earth Planet. Sci. Lett. 44409

Pavich M J, Brown L, Klein J and Middleton R 1984 Earth Planet. Sci. Lett. 68198

Tobailem J 1981 Note CEA-N-1466 (5) Commissanat a' l' Energie Atomique, Centre D' Etudes Nucleaires de Saclay, 91191, Gif Sur Yvette, France

Winsberg L 1956 Geochim. Cosmochim. Acta 9183

Yiou F, Raisbeck G M, Klein J and Middleton R 1984 J. Non-Cryst. Solids 67503

Yokoyama Y, Reyss J L and Guichard F 1977 Earth Planet. Sci. Lett. 3644 